Ross, M.Q. \& Bayer, J.B. (202I). Explicating self-phones: Dimensions and correlates of smartphone selfextension. Mobile Media \& Communication.

Published Version available at: https://doi.org/ I 0.| I 77/2050 I 57920980508

\title{
Explicating self-phones: Dimensions and correlates of smartphone self-extension
}

\author{
Morgan Quinn Ross' and Joseph B. Bayer ${ }^{1,2}$ \\ ' School of Communication, The Ohio State University \\ ${ }^{2}$ Translational Data Analytics Institute, The Ohio State University
}

\begin{abstract}
Given its role as a constant companion, the mobile phone has long been thought of as an extension of the self. However, the psychology of smartphone self-extension has received relatively little attention through empirical research. By explicating theorized facets of selfextension, we explore the dimensionality of smartphone self-extension and examine how established psychological orientations map onto these dimensions. Results provide support for a two-dimensional structure of self-extension. Specifically, we found that self-extension can be delineated on the extent to which the smartphone is viewed as (a) functional for personal goals and (b) integral to personal identity. Across two studies, habitual usage predicted the functionality dimension and problematic usage predicted the identity dimension. In addition, Study 2 revealed that the two dimensions of self-extension corresponded to different dimensions of smartphone vigilance. We discuss the importance of conceptualizing smartphone self-extension as a perceptual construct, as well as the challenges of measuring the psychological connection that exists - or is thought to exist between self and phone.
\end{abstract}

\section{Keywords}

functionality, identity, mobile psychology, self-extension, smartphone, vigilance

The mobile phone has long been regarded as part of the self (Hulme \& Peters, 200I; Turkle, 2008). In fact, as others in the mobile communication literature have noted, the Finnish word for mobile phone, kännykkä, translates to "an extension of the hand" (Campbell \& Park, 2008; Oksman \& Rautiainen, 2003). Over the last decade, the uptake of smartphones has expanded the ways in which mobile technology both informs and reflects the self. Smartphones provide an always-available channel for connecting with other individuals, communities, and societies - and one's self. We express our identities by calling family members, checking work emails, and tracking step counts. Our personal phones serve as a reflection of and repository for many aspects of the self through their digital traces. In addition, the smartphone has a corporeal 
connection to the human body as it is carried about, solidifying its connection to self-processes and self-management in everyday life.

Simply put, the smartphone can be viewed as an extension of the self (Belk, 1988). The self-extension perspective posits that people perceive certain physical objects as part of their selves. Initially grounded in research on consumer behavior (Belk, 1988), the modern selfextension perspective primarily explains how objects obtained throughout the lifetime become integral to one's sense of self. Although scholars have noted the ways early forms of mobile media extend the self, how contemporary devices (hereby "smartphones") relate to self-extension processes and perceptions has received less attention. This is remiss because smartphones are increasingly entangled with the daily presentation of the self.

Working from Park and Kaye's (2019) tripartite conceptualization of self-extension, the current paper has three goals to extend the literature on smartphone self-extension. First, we aim to quantify Park and Kaye's (2019) model, creating and validating self-report measures for each component of self-extension. Second, we test this model in larger samples by conducting two online survey studies. Third, to ground self-extension in the broader literature on the psychology of mobile device use, we investigate its relationship with other foundational constructs, centering on problematic and habitual usage as well as smartphone vigilance. Overall, we aim to provide a theoretical and empirical dive into the concept of smartphone self-extension, emerging with a clearer understanding of the degree to which self-extension represents a distinctive orientation. We first synthesize the existing literature on mobile devices and selfextension, evaluating the extent to which smartphone self-extension represents a multidimensional and perceptual construct. We then overview the connections between selfextension and core psychological models of mobile device behavior before turning to the current two studies. Finally, we discuss implications and challenges for future research on the psychology of mobile device use.

\section{Literature Review}

\section{Self-extension and smartphones}

Although the concept of self-extension first emerged in the 1980s, the boundary between possessions and the self had been interrogated long before. Writing in Principles of Psychology, James (1890) stated that, "a man's Self is the sum total of all that he CAN call his, not only his body and his psychic powers, but his clothes and his house [etc.]" (Chapter 10). Somewhat less starkly, Cooley (1902) argued that possessions could not become incorporated into the self, but could be "assert[ed] as part of [the] self" (p. 188). Perhaps most notably, and specifically attuned to media, McLuhan (1962) declared that "all media. . . are extensions of man that cause. . changes in him" (p. 13). Media can extend the senses across time and space (e.g., a telephone can extend one's hearing across an ocean). While McLuhan advanced a technologically deterministic argument that implied that all media extend all people, his work laid theoretical and linguistic groundwork for the later study of self-extension.

The modern concept of self-extension originated through Belk (1988), who defined the concept as the extent to which "we regard our possessions as parts of ourselves" (p. 139). People are driven to extend themselves in order to fulfill their personal goals or to gain a better understanding of their own identities. A toddler may extend their self into a favorite toy as they discover that their self is different from their environment, or an older person may keep photos 
of their children nearby to serve as reminders of their lives as they age. These examples demonstrate that self-extension changes over the lifetime and can highlight identities at different (e.g., individual, family) levels. Belk argued that people view their possessions as extensions of their selves when they control, create, and/or intimately know their possessions.

This initial line of work, however, emerged prior to the widespread dissemination of mobile phones. The original conception of self-extension applied to a range of identity targets, including possessions, people, places, body parts, ideas, emotions, experiences, money, and pets, but not communication devices (e.g., landline telephones) per se (Belk, 1988). More recently, scholars have argued that mobile phones also represent an extension of self (Hulme \& Peters, 200I; Turkle, 2008), and the rise of smartphones has only fanned these flames. In acknowledgment of these trends, Belk (20I3) updated self-extension to reflect the increasingly digital world (see also Sheth \& Solomon, 20l4), specifying five crucial points of departure from the original concept: dematerialization, re-embodiment, sharing, co-construction of self, and distributed memory. In other words, people increasingly engage with intangible artifacts, reembody themselves with avatars, share content with others, interact with others to construct the self, and use search-based services to supplement their own knowledge.

These points provide guidance for the conceptualization of smartphone self-extension, suggesting that different components of the smartphone can extend the self in different ways that reflect the individual at hand. For example, a person can edit a selfie (i.e., a dematerialized photo) and either keep it for a personal archive or share it with numerous others via social media platforms. Thus, the smartphone is not an extension of the self per se; rather, it bundles various means of extending the self, to the point that the smartphone itself comes to represent an individual's various identities.' Since self-extension can occur in countless ways, the smartphone seems particularly ripe for advancing our understanding of how self-extension manifests both within and across particular objects.

Specifically, the sheer number and variety of self-extending processes afforded by the smartphone suggest that smartphones may represent a departure from Belk's unidimensional conception of self-extension. First, smartphone usage can act as a rapid conduit for the expression of multiple identities, providing a wide array of constant and customizable functionality in a single object (Mutchler et al., 20I I). Second, smartphones serve as a digital repository of past identities by storing digital traces of past usage (e.g., photos; Belk, 2013; Humphreys, 2018; Katz, 2003; Vincent, 2006). Third, smartphone users can aesthetically customize their smartphones to reflect their identities (Lee \& Sundar, 2015; Oulasvirta \& Blom, 2008). Fourth, smartphone users may anthropomorphize their devices (Nass \& Moon, 2000), imbuing voice assistants (e.g., Siri) or the phones themselves with their own identities (Campbell et al., 2020; Schweitzer et al., 2019; Wang, 2017). Fifth, the negative psychological impact of smartphone separation indicates that users may need their devices to feel at ease with their identities in a given moment (Cheever et al., 20I4; Hunter et al., 2018). In sum, while these aspects may not always benefit one's identities (see Turkle, 2008), the connections between smartphones and identities warrant further theorizing related to self-extension.

\section{Smartphone self-extension}

Research on digital and mobile technologies has begun to explore the occurrence of smartphone self-extension. Vishwanath and Chen (2008) found initial cross-cultural support for the notion that people perceive mobile phones as extensions of their selves. Cushing (20I I) and 
Han and colleagues (2017) argued that digital traces (e.g., photos, Facebook profiles, and messaging transcripts) represent an individual's memories, linking them to identity. Moreover, Han and colleagues (2017) found that users who experienced different levels of nomophobia, or the fear of not having one's phone (which was related to self-extension), used different words to describe their smartphones. That is, participants experiencing high nomophobia (and thus selfextension) were more likely to mention words related to the self: "I," "my," "to me," and "part" (p. 423). Finally, Clayton and colleagues (2015) demonstrated that participants reported higher levels of self-extension when they were in possession of their iPhones, suggesting that proximity to the devices increased perceptions of self-extension.

Despite this initial work on smartphone self-extension, questions remain about the underlying conceptualization of self-extension with regard to smartphones. Park and Kaye (2019) interviewed frequent smartphone users and posited three distinct dimensions of self-extension. They defined functional self-extension as how smartphones "expand mental and physical capabilities" (p. 218); anthropomorphic self-extension as how "users attribut[e] their own characteristics to their smartphone[s]" (p. 219); and ontological self-extension as how users derive ontological security or insecurity from their phones, "chang[ing] who they are" (p. 220). Almost all participants experienced functional self-extension, half experienced anthropomorphic self-extension, and some experienced ontological self-extension. Hence, participants suggested that their smartphones extended their identities in distinctive ways.

Collectively, these developments provide a number of insights into the dynamics of smartphone self-extension. First, participants who were near their smartphones or perceived their devices as laden with memories reported higher levels of self-extension. Self-extension thus appears to be highly perceptual, from both visual and symbolic standpoints. Next, smartphone self-extension may consist of multiple dimensions. Park and Kaye's (2019) work suggests that heavy users perceive smartphones as extensions of themselves, but they may do so in very different manners. Unimodal measures of self-extension - typically created by simply substituting "my smartphone" as the subject of items in previous self-extension scales - may miss these or other dimensions of self-extension in this domain.

\section{Self-extension and the psychology of smartphone use}

Self-extension involves the psychological relationship between a user and a device: the extent to which people perceive their phones to be part of their selves. Notably, this perspective has been implicitly or explicitly incorporated into early and ongoing research on the psychology of mobile device use (e.g., Cumiskey \& Ling, 20I5). For example, Walsh and colleagues (Walsh \& White, 2007; Walsh et al., 2010) examined self-identity, or "the extent to which performing a behavior forms part of the individual's self-concept" (Walsh \& White, 2007, p. 24I5). This work found that self-identity predicted heavy mobile phone usage and mediated the effect of prototypical identity - a person's similarity to a prototypical phone user - on phone usage, corroborating our focus on self-perceptions of identity. Early work on nomophobia was also grounded in part on the link between phones and identity. Yildirim and colleagues (Yildirim \& Correia, 20I5; Yildirim et al., 2016) identified “losing connectedness" to one's online self as a key component of nomophobia. More recently, Johannes and colleagues (2019) have investigated vigilance toward smartphones, including their salience to the self in daily life; people's thoughts, as reflections of their selves, can be preoccupied with their mobile devices.

In addition to the preceding research, identity is linked to two other established 
psychological orientations of phone usage: problematic and habitual usage. First, problematic usage involves a heightened salience of the device to the self and posits negative withdrawal symptoms during separation (e.g., Kwon et al., 20l3), implying an over-connection between smartphones and identity. Further, there are strong correlations between self-extension and several problematic usage scales ( $r=.38$ to $r=.62$; Ellis et al., 2019). Second, habits underlie a large proportion of media usage (Wood et al., 2002) - including mobile technology use (Bayer \& LaRose, 2018) - and are more likely to form around behaviors that are particularly important to one's identities (Verplanken \& Sui, 2019). But the relationships between these psychological orientations and different dimensions of self-extension have not been examined. Hence, it is unclear whether self-extension is incorporated within or independent from other wellestablished orientations toward personal phones.

Frameworks of problematic usage primarily view the relationship between the self and phone through the lens of behavioral or clinical addiction. Problematic usage and so-called smartphone addiction are quite similar in that regard (Bianchi \& Phillips, 2005), with current perspectives viewing smartphone addiction as equivalent to (Elhai et al., 2017) or a component of (Kuss et al., 2018) problematic use. Owing to the ongoing debate regarding the legitimacy of applying the addiction framework to smartphones (Pivetta et al., 2019), here we adopt the term problematic usage (Seo et al., 20I5; Vanden Abeele, 2020). Under both self-extension and problematic usage frameworks, people perceive their smartphones as particularly salient objects to the self. Further, without smartphones, people often feel like they are missing a part of themselves, which parallels the withdrawal symptoms experienced by problematic users (Kwon et al., 20I3).

In contrast, habit perspectives do not pathologize smartphone usage, but rather focus on the basic cognitive processes underlying human behavior. Habits involve automaticity, frequency, and identity (Verplanken \& Orbell, 2003). Habit automaticity characterizes behaviors that are linked to cues and can be triggered without control, awareness, intention, and attention (Bayer \& Campbell, 20I2). They are often, but not always, frequently repeated (LaRose, 20I0; Verplanken, 2006). People form habits to achieve important goals and behave according to important values (Verplanken \& Sui, 2019), offloading cognitive resources that would be otherwise required to consciously upkeep their identities. As a result, habits are especially likely to form around possessions, such as smartphones, that are integral to the self.

Both problematic and habitual perspectives, therefore, are closely linked to identity and self-extension processes at a conceptual level. These theoretical links raise questions about the relationship between self-extension and broader psychological orientations toward mobile phones. Thus, beyond testing the theorized dimensions of smartphone self-extension, we also investigated how problematic and habitual tendencies relate to smartphone self-extension. This scope allowed for us to investigate the independence of self-extension from other psychological frameworks, as well as better position identity processes within the literature on the psychology of smartphone usage.

\section{Overview of studies}

Two studies were conducted to understand the dimensionality of smartphone selfextension and potential connections to other psychological orientations. In Study I, we developed self-report measures of functional, anthropomorphic, and ontological self-extension, and examined their relationships with problematic and habitual usage. We anticipated that 
problematic $(\mathrm{HI})$ and habitual $(\mathrm{H} 2)$ usage of the device would be associated with higher perceptions of self-extension, and explored their relationships with the three previously theorized dimensions of self-extension (RQI). In Study 2, we preregistered and replicated the results of Study I with a larger sample and confirmed their robustness by accounting for the role of smartphone vigilance. Our preregistration, anonymized data, analysis scripts, and supplemental materials are available at https://osf.io/nuez3/.

\section{Study I}

\section{Method}

Participants. Participants were recruited via Amazon Mechanical Turk, or MTurk. MTurk provides a more diverse population than other nonprobability samples (Buhrmester et al., 20 I I), and extends recent work that only focused on frequent smartphone users (Park \& Kaye, 20I9). Our initial sample of 247 participants approximated the minimum sample size recommended for scale development (Carpenter, 2018). After excluding participants (see Supplemental Materials), the final sample of I7I people consisted of II 3 males and 58 females. Participants were 33.5 years old on average $(S D=9.16)$ and were paid $\$ 1.50$ for completing the survey, which took an average of 12.1 minutes $(S D=7.25) .^{2}$

Procedure. The study was reviewed and approved by the institutional review board (IRB) at the first author's previous institution. Data were collected in January 2019 through the survey platform Qualtrics. Participants (i.e., MTurkers) entered basic demographic information (age, gender, first language, and education level), information about their phones (when they received their first mobile phone and/or smartphone, the type of phone they currently owned), and average daily smartphone usage (both overall and for certain functions). Next, participants completed measures for smartphone self-extension, problematic usage, habitual usage, and anthropomorphic predisposition. The order of these measures was randomized and items within each measure were randomized for each participant. Finally, participants who reported owning up-to-date iPhones (at least an iPhone 5 with an iOS of 12 or higher) provided information about their average smartphone usage over the last week. They were instructed to open their Settings application, click on Screen Time, and select Last 7 Days at the top of the screen. These iPhone owners then entered their total smartphone usage over the last seven days as well as the average time spent on certain functions. Full measures can be found in Appendix SI. Participants responded to all measures with a seven-point Likert scale from "Strongly disagree" to "Strongly agree" unless otherwise noted. Descriptive and reliability statistics for Study I measures can be found in Table I.

Problematic smartphone usage. Following previous studies (e.g., Wolniewicz et al., 2018), we used the short I0-item version of the Smartphone Addiction Scale (Kwon et al., 20I3) to measure problematic smartphone usage. This scale captures the multifaceted nature of smartphone addiction and is highly related to other measures of problematic use (Davidson et al., 2020).

Habitual smartphone usage. The measure for habitual smartphone usage was based on a previous measure of mobile phone habits (Bayer \& Campbell, 20I2), which was adapted from 
Table I

Descriptive Statistics of Relevant Measures, Study I

\begin{tabular}{llll}
\hline & Mean & Standard Deviation & Cronbach's Alpha \\
\hline Subjective Frequency of Usage & $6.7 \mathrm{I}$ & 5.07 & N/A \\
Semi-Objective Frequency of Usage & 6.23 & 5.78 & N/A \\
\hline Problematic Usage & $3.6 \mathrm{I}$ & $1.5 \mathrm{I}$ & .93 \\
Habitual Usage & 4.89 & 1.13 & .89 \\
Anthropomorphic Predisposition & 3.84 & 1.19 & .87 \\
\hline Functional Self-Extension & 5.58 & 0.82 & .90 \\
Anthropomorphic Self-Extension & 3.92 & 1.36 & .92 \\
Ontological Self-Extension & 3.96 & 1.36 & .93 \\
\hline Functionality & 5.58 & 0.83 & .90 \\
Identity & 3.71 & 1.47 & .96 \\
\hline
\end{tabular}

Note. With the exception of both frequency of usage measures, all measures were composite measures of items scored on a 7-point Likert scale.

the Self-Reported Habit Index (Verplanken \& Orbell, 2003) to measure habits in a frequency independent manner. The lead-in to each statement was modified from "Texting is. .." to "Using my smartphone is. .."

Smartphone self-extension. We followed the scale development guidelines laid out by Carpenter (2018). Three item pools were generated based on the dimensions in Park and Kaye (2019), and further items were added from similar constructs or based on prior literature in order to maximize content validity (see Supplemental Materials). The final item pools contained I 8 functional items, I 5 anthropomorphic items, and I 5 ontological items (see Appendix S3). Each item was a single sentence (e.g., "I use my smartphone to accomplish my goals"). Initial composite scores for each dimension were created by taking the average of each participant's responses to the items (see Table I).

Frequency of smartphone usage. Participants estimated their average daily smartphone usage (i.e., subjective frequency of usage) over the previous week (in hours and minutes), with a reminder that usage included a variety of functions (Lepp et al., 20l4). Participants also entered the average amount of time per day (in hours and minutes) that they spent the previous week on each function. In addition to these estimates, participants with up-to-date iPhones provided the same information based on the Screen Time app (i.e., semi-objective frequency of usage).

Anthropomorphic predisposition. As some people are more likely to anthropomorphize nonhumans (e.g., smartphones) than others, an adapted version of the Individual Differences in Anthropomorphism Questionnaire (see Supplemental Materials) was also measured as a covariate (Waytz et al., 2010). 


\section{Results}

Participants self-reported using their smartphones for almost seven hours a day $(M=6.85$, $S D=5.18)$. A majority $(n=4 I)$ of the 64 iPhone users had iOS I2, allowing access to the Screen Time application to report Apple's measure of logged smartphone usage in addition to the initial subjective measure. Based on this app, participants with updated iPhones reported daily smartphone usage of just over six hours $(M=6.23, S D=5.85)$. Among these participants, there was a strong correlation between subjective and semi-objective (i.e., based on the Screen Time application) reports of the average daily time spent on one's smartphone, $r(39)=.57, p<.00$ I (similar to prior comparisons; e.g., $r=.48$; Ellis et al., 2019). Moreover, after removing three clear outliers, the correlation between subjective and semi-objective reports increased considerably, $r(36)=.91, p<.001 .^{3}$ As such, the subjective reports of smartphone usage supplied by all participants were used for the remainder of the analyses.

Dimensions of smartphone self-extension. A large correlation between anthropomorphic and ontological self-extension, $r(169)=.87, p<.001$, suggested significant overlap between these dimensions. Moreover, a Bartlett's test of sphericity was significant, $\chi^{2}(\mathrm{I} I 28)=5627, p<.00 \mathrm{I}$, and the Kaiser-Meyer-Olkin (KMO) value of .9l was well above the recommended value of .60 (Carpenter, 2018), indicating that factor analysis was appropriate. As such, we conducted exploratory factor analyses on the overall scale to assess possible multi-dimensionality. Following Carpenter's (2018) recent recommendations, we ran a common factor analysis with principal axis factoring and promax rotation using the "psych" package in R (Revelle, 20I9), which found two factors based on examination of the scree plot and parallel analysis. An item was retained if it only loaded onto one factor with a factor loading greater than .32 (in terms of absolute value). Twenty-five items loaded onto the first factor and 18 loaded onto the second factor, which together accounted for $48 \%$ of the total variance. Items that contributed to neither of the factors were eliminated $(n=5)$. This procedure was repeated on the remaining items, yielding two factors with all items loading onto only one of the factors (see Table SI).

In line with the high zero-order correlation between anthropomorphic and ontological self-extension, one factor (identity) included 13 items from the anthropomorphic self-extension subscale and 12 items from the ontological self-extension subscale. All of these 25 items centered on the phone as a crucial facet of one's identities. In contrast, the second factor (functionality) included 13 items from the functional self-extension subscale along with one item from both anthropomorphic and ontological self-extension. These 15 items referred to the broad functionality of the device in terms of fulfilling personal goals. Both factors were highly reliable (identity: $\alpha=.96$; functionality: $\alpha=.90$ ). Composite scores for each factor were created by taking the average of each participant's responses to the respective items (identity: $M=3.7 \mathrm{I} ; S D=I .47$; functionality: $M=5.58, S D=0.83$ ). Descriptive statistics and reliability measures can be found at the bottom of Table I, while bivariate correlations between the dimensions of self-extension and other measures can be found in Table S2.

Predictors of smartphone self-extension. To test our hypotheses that problematic $(\mathrm{HI})$ and habitual $(\mathrm{H} 2)$ smartphone usage would predict greater self-extension, and explore how they relate to its dimensions (RQI), we conducted ordinary least square (OLS) regression analyses. We ran separate OLS regressions for each of the three theorized dimensions (functional, anthropomorphic, and ontological self-extension), as well as the two resultant dimensions of 
functionality and identity (Table 2 and 3). Anthropomorphic predisposition and frequency were included as control covariates. ${ }^{4}$ Given moderate heteroskedasticity, we also ran robust regressions for the functional and functionality models using the "MASS" package in R (Venables \& Ripley, 2002), which met more stringent assumption checks. Importantly, the pattern of results did not change (see Table S3).

We then specified separate models for the three theorized dimensions of self-extension. We found that functional self-extension was only predicted by habitual usage, $b=.5 \mathrm{I}, p<.00 \mathrm{I}$. Next, anthropomorphic self-extension was predicted by problematic usage, $b=.54, p<.00 \mathrm{I}$, as well as the control covariate of anthropomorphic predisposition, $B=.35, p<.00$, but not habitual or frequent usage. Finally, ontological self-extension was also predicted by only

Table 2

OLS Regression Analyses Predicting Theorized Dimensions of Self-Extension, Study I

\begin{tabular}{|c|c|c|c|c|c|c|}
\hline & \multicolumn{2}{|c|}{ Functional } & \multicolumn{2}{|c|}{ Anthropomorphic } & \multicolumn{2}{|c|}{ Ontological } \\
\hline & $\beta$ & $t$ Value & $\beta$ & $t$ Value & $\beta$ & $t$ Value \\
\hline Anthropomorphic Predisposition & -.05 & -0.47 & $.35 * * *$ & 5.66 & $.16 * * *$ & 2.95 \\
\hline Frequency & .10 & I.4I & .01 & 0.22 & .05 & 1.30 \\
\hline Problematic Usage & -.20 & -2.84 & $.54 * * *$ & 7.79 & $.72 * * *$ & 12.10 \\
\hline Habitual Usage & .5 | **** & 6.42 & .03 & 0.52 & .07 & I.57 \\
\hline $\mathrm{R}^{2}$ & \multicolumn{2}{|c|}{$.215 * * *$} & \multicolumn{2}{|c|}{$\begin{array}{l}.699 * * * \\
(\mathrm{df}=166)\end{array}$} & \multicolumn{2}{|c|}{$\begin{array}{l}.775 * * * \\
(\mathrm{df}=166)\end{array}$} \\
\hline
\end{tabular}

Note: $* p<.05, * * p<.01, * * * p<.00 \mathrm{I}$.

Table 3

OLS Regression Analyses Predicting Resultant Dimensions of Self-Extension, Study I

\begin{tabular}{|c|c|c|c|c|}
\hline & \multicolumn{2}{|c|}{ Functionality } & \multicolumn{2}{|c|}{ Identity } \\
\hline & $\beta$ & $t$ Value & $\beta$ & $t$ Value \\
\hline Anthropomorphic Predisposition & -.06 & -0.63 & $.29 * * *$ & 5.66 \\
\hline Frequency & .11 & 1.65 & .00 & 0.13 \\
\hline Problematic Usage & $-.18 * *$ & -1.65 & $.66 * * *$ & I I.52 \\
\hline Habitual Usage & $.50 * * *$ & 6.03 & .00 & 0.10 \\
\hline $\mathrm{R}^{2}$ & \multicolumn{2}{|c|}{$\begin{array}{l}.2 \mid 4^{* * *} \\
(\mathrm{df}=166)\end{array}$} & \multicolumn{2}{|c|}{$\begin{array}{l}.793 * * * \\
(\mathrm{df}=166)\end{array}$} \\
\hline
\end{tabular}

Note: $* p<.05, * * p<.01,{ }^{* * *} p<.001$. 
problematic usage, $b=.72, p<.00 \mathrm{I}$, and anthropomorphic predisposition, $b=.16, p<.0 \mathrm{I}$. In sum, habitual usage predicted functional self-extension and problematic usage predicted anthropomorphic and ontological self-extension (providing partial support for $\mathrm{HI}$ and $\mathrm{H} 2$ and evidence for RQI).

We also conducted models using the dimensions resulting from the exploratory factor analyses as outcome variables. We found that functionality was only predicted by habitual usage, $b=.50, p<.001$. However, identity was predicted by problematic usage, $b=.66, p<.00 \mathrm{I}$, and anthropomorphic predisposition, $B=.29, p<.001$. These results mirror the above findings, but with anthropomorphic and ontological self-extension collapsed onto identity self-extension, providing further support for two-factor (vs. three-factor) dimensionality.

\section{Discussion}

In Study I, we evaluated the validity of smartphone self-extension as a multi-dimensional orientation. Our results offered partial support for this more nuanced perspective on smartphone self-extension, as two factors - which we termed functionality and identity - emerged as distinguishable. Functionality involves viewing the phone more as a "tool" that extends the self by fulfilling personal goals, whereas identity consists of perceiving the device more as an "amulet" that extends the self by bolstering one's identities. Hence, despite past attention to three separate facets of self-extension, our analyses revealed that anthropomorphic and ontological selfextension generally loaded onto the same factor (identity), while functional self-extension loaded onto its own factor (functionality). Moreover, problematic and habitual usage were positively associated with identity and functionality, respectively, providing further evidence of a two-part divide in perceived self-extension.

These results place smartphone self-extension at the nexus of two of the primary perspectives on the psychology of mobile communication. Problematic and habitual frameworks seem to encompass two significantly different viewpoints on the relationship between self and phone. A habitual smartphone user is more likely to view their smartphone as an extension of the personal goals that they can achieve. Alternatively, a problematic smartphone user is more likely to view their device as an extension of the person that they can be. This contrast suggests that how people interpret their mobile behavior - as an everyday habit versus a potential problem - is closely linked to how they make sense of the mobile device itself.

\section{Study 2}

Thus far, we have attempted to map different dimensions of self-extension onto problematic and habitual orientations, two of the primary psychological frameworks used in the mobile media literature. In Study 2, we had two primary goals. First, we sought to replicate the results of Study I using a larger sample with preregistered analyses. Specifically, we aimed to corroborate the two-factor model of smartphone self-extension, as well as the hypotheses that problematic $(\mathrm{HI})$ and habitual $(\mathrm{H} 2)$ smartphone usage would be associated with identity and functionality self-extension, respectively. Second, to test the robustness of these relationships, we also sought to account for additional individual differences that may underlie the psychological connection between smartphones and the self. The findings of Study I reaffirm the covariation seen across various psychological constructs measuring the relationship between user and phone (e.g., self-extension, addiction, nomophobia; Ellis et al., 2019). As such, they also raise the question 
of whether smartphone self-extension may emerge from a more basic psychological orientation toward mobile communication.

Most notably, recent work has highlighted the role of online vigilance - one's "psychological connectedness" to the online world (Reinecke et al., 2018) - as a fundamental orientation toward always-on connectedness. Vigilance involves the broader ecosystem of online media, whereas self-extension is typically applied to individual objects (such as smartphones). However, by affording anytime-anyplace connectivity, smartphones represent one of the primary means to stay vigilant to the online world (Johannes et al., 2019). Constant connectedness provides users with the latitude to deeply integrate smartphones into their lives and identities, suggesting that online vigilance can facilitate self-extension (Vanden Abeele et al., 20I8). In addition, vigilance is distinct from yet closely related to facets of both habitual and problematic mobile usage (Reinecke et al., 2018), making it an important covariate to test the robustness of the relationships found in Study I. Therefore, in Study 2 we investigated whether the psychological connection between users and their digital devices may in fact reflect a broader connection between users and their digital worlds.

\section{Method}

Participants. We recruited 525 participants on Amazon Mechanical Turk. After excluding participants for the same reasons as Study $1,{ }^{5}$ and an additional two participants who flagged bot detection (not preregistered), the resulting sample of $45 \mathrm{I}$ people consisted of 234 males, 2 I 2 females, and 5 people who identified as another gender or preferred not to share. Participants were $4 \mathrm{I} .87$ years old on average $(S D=12.4 \mathrm{I})$ and were paid $\$ 1.30$ for completing the survey, which took an average of 6.68 minutes $(S D=4.31)$.

Procedure. The study was reviewed and approved by the IRB at the authors' institution. Data were collected in January 2020 using the survey platform Qualtrics. Participants were restricted to smartphone owners located in the United States. Full measures are reported in Appendix S2. In contrast to Study I, the measures in Study 2 were presented in matrix format (vs. separate multiple-choice questions). In addition, the Study I questions pertaining to phone information, usage of smartphone functions, and anthropomorphic predisposition were excluded. The measures for habitual and problematic usage were identical to Study I. As detailed below, the self-extension and frequency measures were adjusted and a smartphone vigilance scale was added. ${ }^{6}$ Descriptive and reliability statistics for Study 2 measures can be found in Table S4.

Smartphone self-extension. The smartphone self-extension measure was shortened to 12 items based on item loadings and face validity considerations. Some items with high item loadings were not used due to over-specificity and conceptual overlap with more straightforward item wordings (see Table SI). All items included in the short scale had items loadings greater than .80 (identity) or .60 (functionality) in Study I.

Frequency of usage. Study 2 adopted a different measure of frequency, following the recommendation of Boase and Ling (20I3) that "how often" frequency measures exhibit higher validity than "how much" measures (used in Study I). As such, participants in Study 2 were asked how often they used their smartphones and responded on a nine-point scale from "Less than once a week" to "About every five minutes." 
Smartphone Vigilance. We adapted the smartphone vigilance scale from Johannes et al. (2019), which is based on Reinecke et al.'s (2018) scale of online vigilance. Online vigilance consists of three dimensions: salience, the user's cognitive awareness of online media; reactibility, the user's propensity to attend to signals from online media (e.g., notifications); and monitoring, the user's motivation to monitor online media for new information (Reinecke et al., 2018). To fit the current study, we adjusted the item wordings to refer to smartphone vigilance in general (vs. during a specific task). The resulting measure included nine items with a seven-point Likert scale from "Strongly disagree" to "Strongly agree." Three items were associated with each of the three subscales, and the overall measure and the subscales displayed high reliability.

\section{Results}

A confirmatory factor analysis was run to verify the two-factor model found in Study I. The model demonstrated acceptable fit, $\chi^{2}(19)=176.7, p<0.001, \mathrm{CFI}=0.95$, RMSEA $=0.07$, SRMR $=0.057$ (Hu \& Bentler, 1999). Moreover, the top modification indices involved items within either of the two factors, suggesting that no clear improvements could be made. The two factors exhibited a small-to-moderate correlation, $r(449)=.23, p<.00 \mathrm{I}$, similar to Study I, indicating slightly related but ultimately distinct factors. Figure I displays the bivariate correlations between the key measures in Study 2. Generally, vigilance was strongly correlated with both problematic and habitual use, and all three exhibited moderate correlations with frequency and moderate-tostrong correlations with functionality and identity.

Confirmatory models. To test our hypotheses that problematic $(\mathrm{HI})$ and habitual $(\mathrm{H} 2)$ smartphone usage would predict self-extension, we conducted separate OLS regression analyses to predict functionality and identity (Table 3). Frequency was included as a covariate in all models. ${ }^{7}$ Owing to heteroskedasticity, we also ran robust regressions for functionality and used a log transformation of identity, which met more stringent assumption checks. Importantly, the pattern of results did not change (see Table S5). We found that functionality was predicted by habitual usage, $b=.40, p<.001$, and frequent usage, $b=.28, p<.001$, but not by problematic usage. Conversely, identity was positively predicted by problematic usage, $B=.56, p<.00 \mathrm{I}$, and habitual usage, $b=.14, p<.001$, but negatively predicted by frequent usage, $b=-.13, p<.001$. As a result, we replicated the results of Study I, finding evidence to support the link between problematic usage and identity $(\mathrm{HI})$ and habitual usage and functionality $(\mathrm{H} 2)$. In contrast to Study I, frequency was positively related to functionality and negatively related to identity, further suggesting two distinct perceptions of self-extension.

Exploratory models. To investigate the relationship between smartphone self-extension and vigilance, we specified additional OLS regressions that included the above predictors as well as the three dimensions of smartphone vigilance. The initial model exhibited high multi-collinearity (VIF > 4) due to the strong intercorrelations between the dimensions of smartphone vigilance. As such, we ran separate models for each dimension (see Table 4). Across these models, the three dimensions of online vigilance positively predicted functionality and identity, with the exception of salience, which marginally and negatively predicted functionality, $b=-.12, p<. I$. However, in all models habitual and problematic usage retained the highest standardized coefficients for functionality and identity, respectively (see Table S6 for bootstrapping results in support of the stronger role of habitual and problematic usage). 


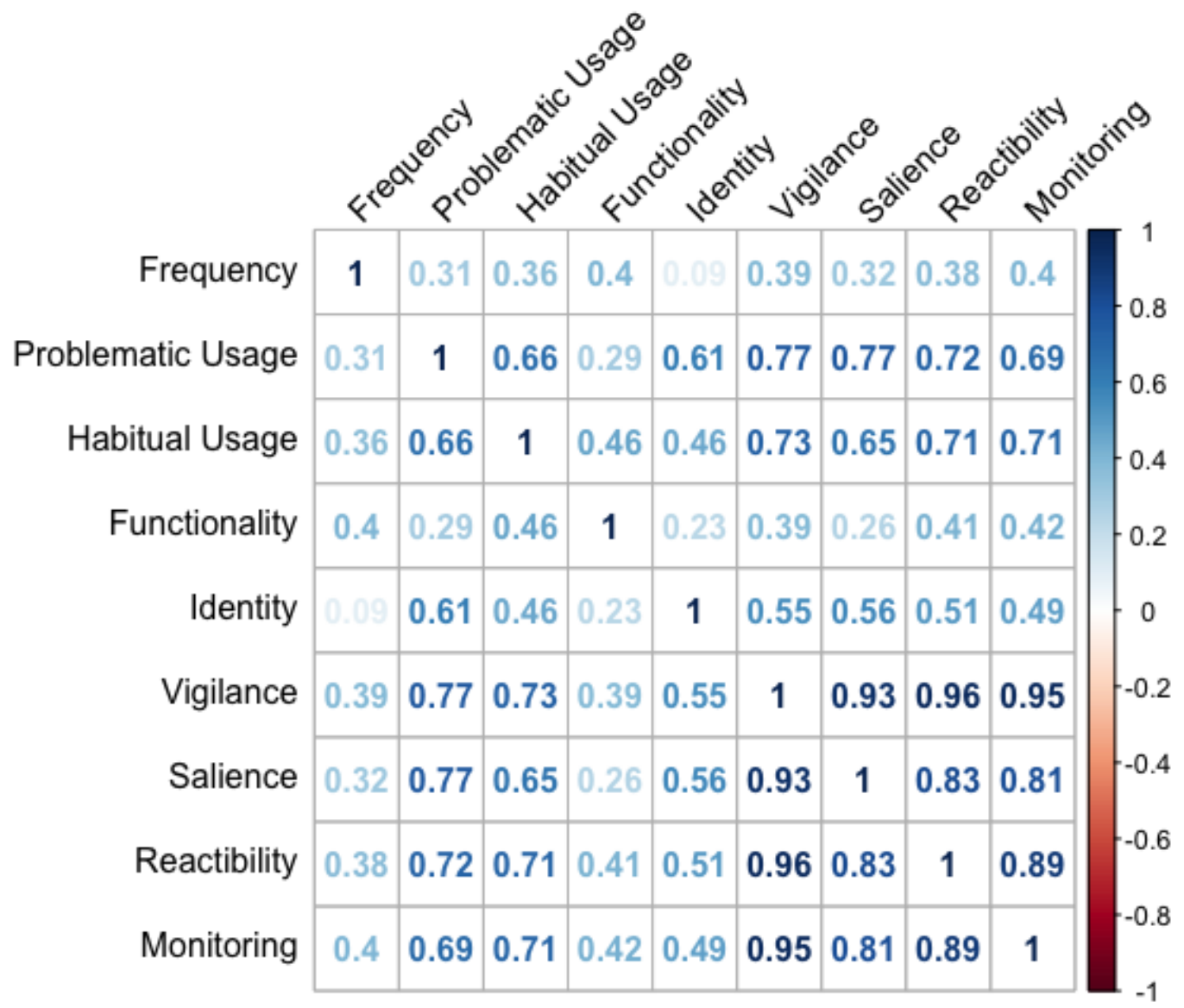

Figure 2. Correlation Matrix of Relevant Measures, Study 2

Note: Every correlation was significant at the $p<.00 \mathrm{I}$ level except frequency and identity.

\section{General Discussion}

To gain a better theoretical and empirical understanding of the relationship between smartphones and self-processes, the current research examined the dimensionality of smartphone self-extension. Two distinct dimensions of self-extension - functionality and identity - emerged, referring to perceptions of the device as integral to one's personal goals (functionality) or one's sense of self (identity). Moreover, we tested the resulting dimensions of self-extension in relation to established psychological orientations toward mobile phones: problematic and habitual usage, as well as smartphone vigilance. As a whole, the studies reaffirm the centrality of identity processes for understanding the psychology of mobile device use.

These findings offer a number of implications for future research. First, smartphone selfextension appears to be multi-dimensional. Our studies provide both supportive and counter evidence with regard to past work on the dimensionality of self-extension. Specifically, two dimensions that were found in earlier qualitative work - anthropomorphic and ontological selfextension (Park \& Kaye, 2019) - were statistically indistinguishable in both of our samples. In our two-factor solution, both anthropomorphic and ontological self-extension mapped on to what we termed identity self-extension. Whether a part of the self or merely a reflection of the self, 
Table 3

OLS Regression Analyses Predicting Functionality and Identity, Study 2

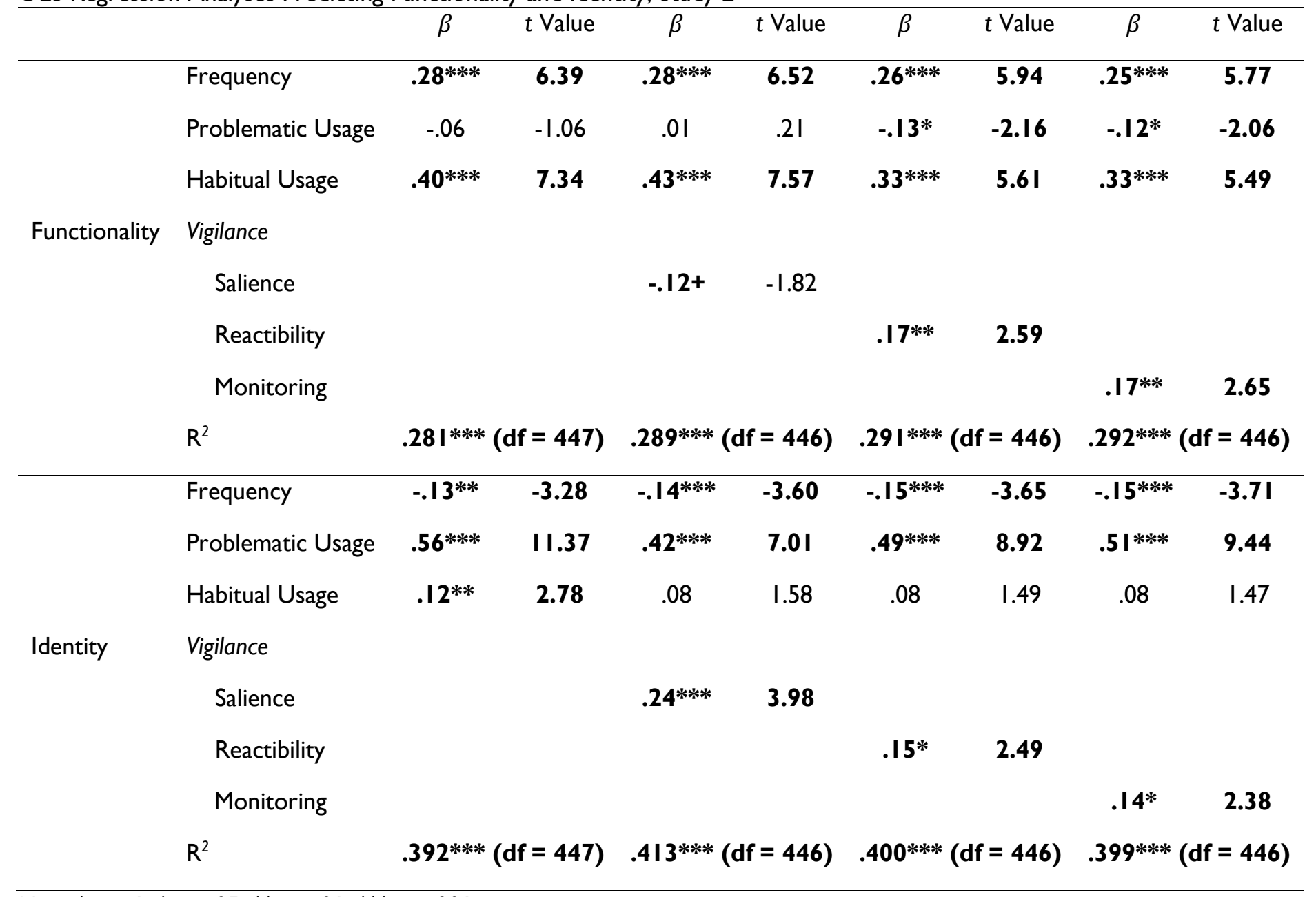

Note: ${ }^{+} p<.1,{ }^{*} p<.05,{ }^{*} p<.01,{ }^{* * *} p<.00 \mathrm{I}$ 
the phone is integral to the identities of some individuals. On the other hand, we found support for the separate role of functional self-extension (or functionality in our two-factor solution) in line with the theorized dimensionality.

The two resultant dimensions exhibited different relationships with habitual and problematic usage, corroborating the two-part divide in perceptions of smartphone selfextension. In Study I, problematic usage predicted identity and habitual usage predicted functionality, and in Study 2 we preregistered and replicated these findings in a larger sample. We thus demonstrate a link between habitual usage and perceived functionality, indicating that viewing the phone as a practical, all-purpose tool is tied to a more automatic orientation. Conversely, problematic usage was associated with perceived identity, which suggests that negative outcomes of smartphone usage (e.g., daily-life disturbance) are potentially linked to deeply identifying with the device. At the same time, these connections suggest that self-processes can help to bridge problematic and habitual perspectives on the psychological underpinnings of mobile device use by focusing on the role of identity (Bayer et al., 2016).

We also affirmed the robustness of these findings by including smartphone vigilance as an additional predictor in Study 2. Problematic and habitual use remained strong predictors of selfextension when any dimension of smartphone vigilance was included in our models. In addition, the inclusion of smartphone vigilance provided further evidence for the multi-dimensionality of self-extension. Reactibility and monitoring, or the attention toward and motivation to monitor the device, were related to both identity and functionality self-extension. However, salience the degree to which users are cognitively aware of their devices - was an important marker of identity in our models, but marginally and negatively predicted functionality. Compared with people who viewed their smartphones as crucial to their personal goals, those who viewed their phones as integral to their personal identities were more likely to have their devices at the top of their minds (i.e., salient). Such thoughts may be beneficial due to the perceived importance of the device (Reinecke et al., 20l8), but also turn into detrimental rumination (Walsh et al., 20l0), helping to explain the stronger association between identity and problematic usage (see Freytag et al., 2020).

Our results collectively highlight the importance of accounting for how users think about - and make sense of - both their behavioral and their cognitive connections to their devices. On the whole, the distinction between identity and functionality was not captured by the most behavior-focused measures. Study I demonstrated that neither identity nor functionality were associated with overall frequency or usage of specific functions. In Study 2, both reactibility and monitoring - the more behavioral components of vigilance - were associated with both identity and functionality. ${ }^{8}$

As such, the identity-functionality divide may instead result from users evaluating different aspects of their connection with their device rather than displaying different mobile behaviors. Those who experience functionality self-extension may focus more on their observable behaviors, noting that they habitually react to and monitor their mobile devices. By contrast, those who report identity self-extension may also take into account cognitive salience or psychological turmoil associated with the device, evaluating their mental state in addition to their behavior. Measuring smartphone self-extension, perhaps even more so than other self-reports in mobile media psychology, may depend on the user's frame of reference or meta-cognition, above and beyond their objective behavior. The user's "meta-perception" of their mobile media usage may constitute a form of "lay theory" (i.e., folk theories; Kanthawala et al., 2019) that can drive 
behavior. For example, while using a smartphone problematically can have negative effects, thinking that one uses a smartphone problematically can also have downstream consequences (e.g., losing the capacity to enjoy using the device without guilt; Lanette et al., 2018). Given that narratives alone have been shown to temporarily extend the self (Slater et al., 20I4), the current research affirms the necessity of understanding how self-perception processes underlie the psychological connections that users have with their devices.

Smartphone self-extension also informs the study of self-extension more broadly. Selfextension should be further investigated as a potential multi-dimensional construct, with specific emphasis on its perceptual nature. Our study is particularly relevant for applying self-extension to emergent mobile media and technologies. The first Apple Watch was released in 20I5, and the recently released Amazon Halo purports to quantify one's halo (i.e., positive traits; Swisher, 2020). Hence, implanted versions of similar technology may be closer to our future lives than suggested by sci-fi films (Frith, 2019). The moderate levels of self-extension observed in the current study suggest that some people - or at least voluntary survey participants - are warming to the integration of mobile media and the self (cf. Melumad \& Pham, 2020), even though the technology remains external. It is plausible that wearable or implanted mobile media, even if they possess fewer functions than a smartphone, will amplify self-extension processes.

The preceding implications must be offered alongside a number of limitations, which also inform future research. First, our arguments regarding the dimensionality of self-extension are predicated on our operationalization of prior theoretical constructs. As such, the lack of differentiation between anthropomorphic and ontological self-extension may be due to measurement choices. Specifically, our quantitative approach, which required participants to agree or disagree to certain statements, may be less equipped to disentangle nuances in user perceptions of self-extension than a more holistic, qualitative approach. To compensate for this drawback, future empirical work might consider richer quantitative measures, such as providing vignettes that reflect different components of self-extension. Overall, it is imperative that future research continues to probe perceptions of self-extension using qualitative methods, in order to deeply investigate its contours and bolster quantitative studies of self-extension.

In addition, this work surfaced concerns regarding the validity of functionality and identity self-extension. Most significantly, it could be argued that functionality is not a valid form of selfextension. As Belk (1989) notes, extending the self to include an umbrella would be uncommon, as "the umbrella and its potential loss are most commonly functional concerns" (p. 130). While we argue that a smartphone is unlike an umbrella - the multi-functionality and mobility of the smartphone enable the device to fulfill many personal goals at any moment - further work here is needed, perhaps drawing from literature in psychology on how behavior fits into identity (see Morin, 2017). Moreover, identity self-extension may be confounded with problematic usage or certain personality traits. Given its high correlation with problematic usage (Study I: $r=.87$; Study 2: $r=.6 \mathrm{I}$ ), identity self-extension could be a more value-neutral alternative to some clinical addiction models. Similarly, identity self-extension covaried with anthropomorphic predisposition and may covary with other individual differences; for example, the device may be more salient for those who are attuned to frequent phone behaviors such as socializing (e.g., extroverts).

These concerns dovetail with methodological challenges in the current study. Figure 2 displays histograms for functionality and identity self-extension. Functionality has a clear floor, which was only somewhat mitigated by the short scale. This floor concurs with previous work (Park \& Kaye, 2019) and indicates that functionality may be a precursor to or sub-component of identity. In contrast, the short scale for identity was somewhat positively skewed in Study I, but 
Study 1: Functionality (Full)

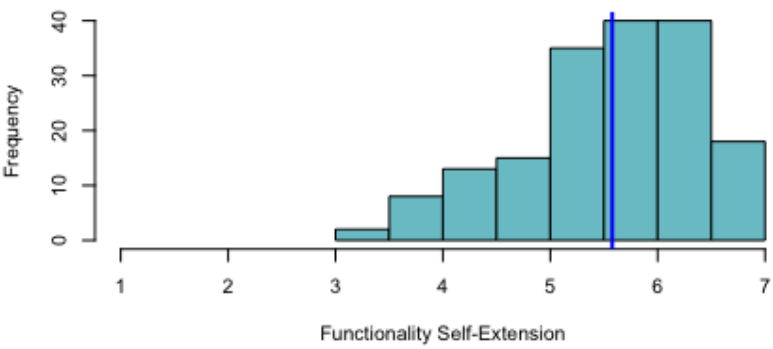

Study 1: Functionality (Short)

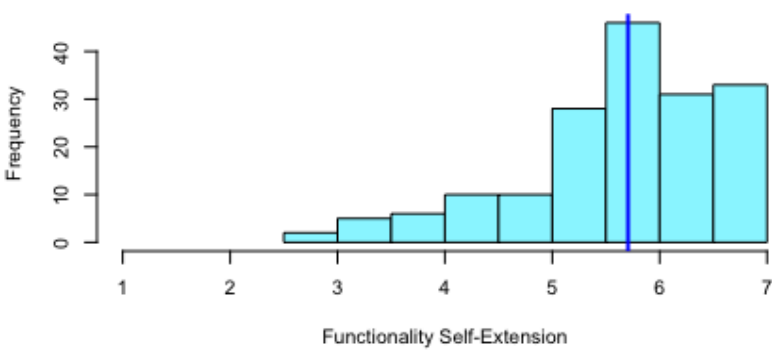

Study 2: Functionality (Short)

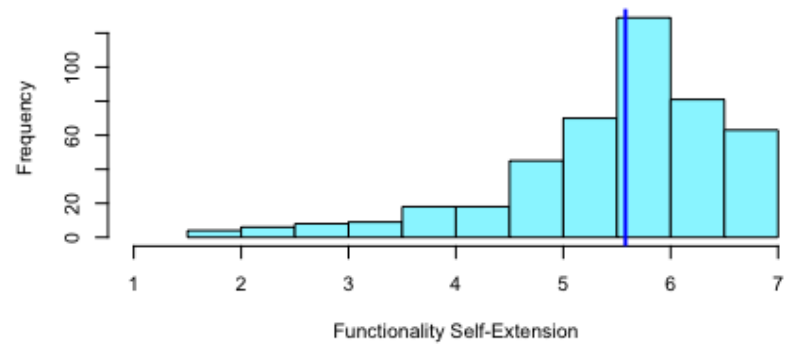

Study 1: Identity (Full)

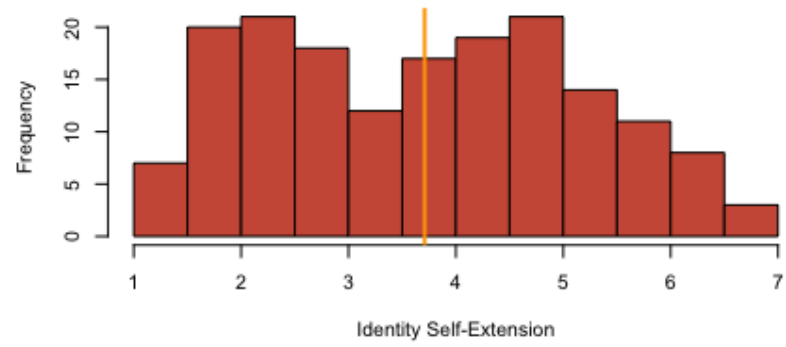

Study 1: Identity (Short)

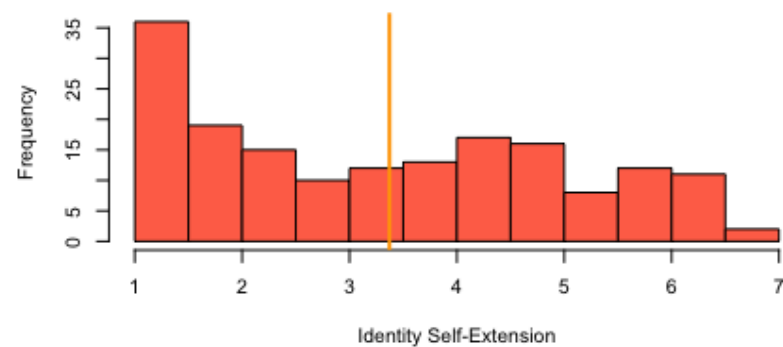

Study 2: Identity (Short)

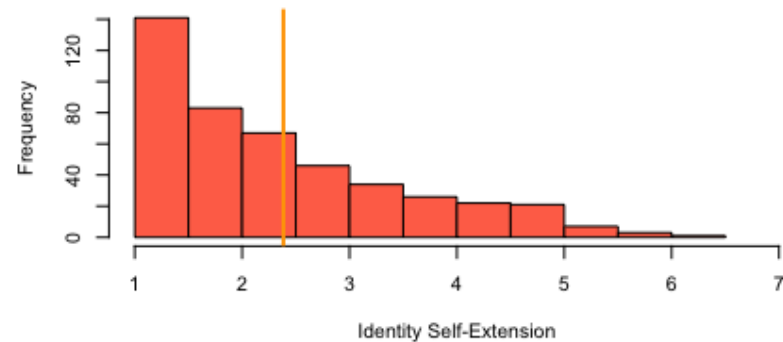

Figure 2. Histograms and Means of Full- and Short-Form Measures of Functionality and Identity Self-Extension in Study I and Study 2.

Note. The blue lines display the means of the functionality scale and the orange lines show the means of the identity scale. The darker colors refer to the full scales and the lighter colors refer to the short scales.

the skew increased considerably and unexpectedly in Study 2, leading to a one-point reduction from the full-scale average in Study I. While the lower levels of identity reflect previous work (Park \& Kaye, 2019), the sizable shift of identity in Study 2 suggests a high degree of variability and/or malleability in self-extension perceptions. In Study I, participants first estimated how much they used their phones, both overall and for specific functions, and then responded to selfextension items individually. In contrast, participants in Study 2 estimated their phone use at the end of the survey and responded to self-extension items collectively in a matrix scale. It is possible that participants self-reported less identity self-extension in our second study when they had not elaborated how they used their phone and could have weighed items against each other (i.e., participants may have disagreed with the identity items more forcefully when comparing them with functionality items). ${ }^{9}$ 
Moreover, the potential role of perceptual biases in our measurement may be heightened due to the abstract nature of the identity self-extension items. Unlike functionality items, identity items (e.g., "My smartphone is central to my identity") may heavily rely on subjective interpretations of words such as "central" and "identity." Arguably, people who agreed with the abstract identity items were indeed experiencing identity self-extension. People who experience nomophobia (which is related to self-extension) use distinctive words to describe their devices (Han et al., 20I7), suggesting that the abstract items could have synced with their perceptions of their mobile devices. Lay theories about smartphone use could even drive these perceptions of normative discourse; people who focus on their concrete behavior may reject the abstract identity items, whereas people who focus on their mental states may actually overreport identity self-extension if they often consider the device in abstract terms. Furthermore, perceptions of mobile phones fluctuate over time and across contexts (Park \& Kaye, 2019), and this dynamic interplay may explain usage and outcomes (Vishwanath \& Chen, 2008). Future studies, perhaps employing experience sampling (Schnauber-Stockmann \& Karnowski, 2020), could elucidate these perceptual processes and how they operate across situations in daily life.

Finally, while this research provides guidance for studying self-extension beyond smartphones, its results only generalize to smartphone users. Smartphones are uniquely personal and multi-functional mobile devices, potentially leading to quantitatively higher and qualitatively different self-extension compared to other objects. Our generalizability is further hindered by our MTurk sample of American adults with varying levels of smartphone use. We extended previous findings on self-extension from a South Korean sample of heavy smartphone users (Park \& Kaye, 2019), but future research should investigate self-extension in more representative samples of additional geographic regions through probability sampling. Such work is essential given prior work showing that mobile phones are viewed as extensions of the self - but used differently - across cultures (Vishwanath \& Chen, 2008).

\section{Conclusion}

The current studies shed light on the dimensional nature of self-extension, validating two dimensions of smartphone self-extension and linking them to established psychological orientations. In doing so, we underline the significant role of individual differences in how people perceive their mobile behavior and make sense of their psychological connection with the device. As mobile media become synced to the self in novel and increasingly proximal ways, self-extension will continue to be an integral perspective for understanding the psychological links between user and device. To that end, future work will be challenged to identify the multivalent understandings of self-phone links among users themselves, and thereby unpack the contributions of mobile media to identity construction.

\section{Author note}

An earlier version of this paper was submitted in partial fulfillment of the requirements for the degree of Bachelor of Arts in Cognitive Science at Carleton College. 


\section{Acknowledgements}

We thank Scott W. Campbell and Kathleen Galotti for their guidance and Ahmed Abdirahman, Russell Belk, Roy Elveton, Rich Ling, Elliot Schwartz, and Valerie Umscheid for their helpful comments on this project.

\section{Funding}

The authors received no financial support for the research, authorship, and/or publication of this article.

\section{ORCID iD}

Morgan Quinn Ross: https://orcid.org/0000-000I-74I6-985I

\section{Supplemental material}

Supplemental material for this article is available at https://osf.io/nuez3/.

\section{Notes}

I. In line with contemporary scholarship on identity in psychology (e.g., Oyserman et al., 2017), we consider the self to contain myriad identities that dynamically fluctuate in salience as a function of context. Here, we focus on how an individual can extend multiple identities through the many capabilities of smartphones, and thus extend their overall self in aggregate. As such, we view smartphone self-extension as a specific identity-based process that is linked to broader conceptualizations of identity as well as multiple selfprocesses studied in the psychological literature (Morin, 2017).

2. We re-ran analyses without exclusions - with the exception of incomplete responses to the self-extension measure, which were necessary to run the factor analyses - and the pattern of results did not change.

3. This high correlation may indicate that participants checked Screen Time when providing their subjective estimates of smartphone usage, or that participants who use Screen Time are simply more aware of how much they use their phones (see the Supplemental Materials for further discussion).

4. We re-ran all analyses without these covariates. The overall pattern of results was the same, with the additional result that problematic usage negatively predicted both functional self-extension, $b=-.23, p<.0 \mathrm{I}$ and functionality self-extension, $b=-.2 \mathrm{I}, p<$ $.0 \mathrm{I}$ (which would provide further evidence for a two-part divide in self-extension).

5. The overall pattern of results did not change when the excluded data was retained.

6. Two additional measures - self-expansion and alternate versions of the self-extension measure - were also included but are not discussed in the main manuscript (see Supplemental Materials for full reporting of these measures).

7. We once again re-ran these analyses without frequency. The overall pattern of results did 
not change.

8. Our conflicting results regarding frequency - perhaps due to the alternative measure used in Study 2 - suggest that more work is needed to measure frequency and relate it to psychological constructs.

9. Another interesting finding in this vein, reported in the Supplemental Materials, is that Study 2 participants who responded to the problematic usage scale immediately before the self-extension measure reported marginally lower levels of functionality and identity self-extension, suggesting that the wording of the problematic usage scale may have encouraged participants to distance themselves from their devices.

\section{References}

Bayer, J. B., \& Campbell, S. W. (20I2). Texting while driving on automatic: Considering the frequencyindependent side of habit. Computers in Human Behavior, 28(6), 2083-2090. https://doi.org/I0.10I6/j.chb.20I2.06.0I2

Bayer, J. B., Dal Cin, S., Campbell, S. W., \& Panek, E. (2016). Consciousness and self-regulation in mobile communication. Human Communication Research, 42(I), 7I-97. https://doi.org/I0.1 I I I/hcre. 12067

Bayer, J. B., \& LaRose, R. (2018). Technology habits: Progress, problems, and prospects. In B. Verplanken (Ed.), The psychology of habit (pp. II I-I30). Springer. https://doi.org/I0.1007/978-3-3 I9-97529-0_7

Belk, R. (1988). Possessions and the extended self. Journal of Consumer Research, 15(2), 139. https://doi.org/I0.1086/209/54

Belk, R. (1989). Extended self and extending paradigmatic perspective. Journal of Consumer Research, I6(I), I29-132. https://www.jstor.org/stable/2489310

Belk, R. (20I3). Extended self in a digital world. Journal of Consumer Research, 40(3), 477-500. https://doi.org/I0.1086/67/052

Bianchi, A., \& Phillips, J. G. (2005). Psychological predictors of problem mobile phone use. Cyberpsychology and Behavior, 8(I), 39-5I. https://doi.org/I0.I089/cpb.2005.8.39

Boase, J., \& Ling, R. (20/3). Measuring mobile phone use: Self-report versus log data. Journal of ComputerMediated Communication, 18(4), 508-5 I9. https://doi.org/I0.I I I I/jcc4.I202I

Buhrmester, M., Kwang, T., \& Gosling, S. D. (20II). Amazon's mechanical Turk: A new source of inexpensive, yet high-quality, data? Perspectives on Psychological Science, 6(I), 3-5. https://doi.org//0.II77//74569/610393980

Campbell, S. W., \& Park, Y. J. (2008). Social implications of mobile telephony: The rise of personal communication society. Sociology Compass, 2(2), 37I-387. https://doi.org/I0.1 I I I/j. I75 I9020.2007.00080.x

Campbell, S. W., Wang, E. (Wenhuan), \& Bayer, J. B. (2020). Mobiles and the self: A trajectory of paradigmatic change. In R. Ling, L. Fortunati, G. Goggin, S. S. Lim, \& Y. Li (Eds.), The Oxford handbook of mobile communication and society (pp. 42-53). Oxford University Press. https://doi.org/I0.1093/oxfordhb/9780190864385.013.3

Carpenter, S. (2018). Ten steps in scale development and reporting: A guide for researchers. Communication Methods and Measures, I2(I), 25-44. https://doi.org//0.1080/193/2458.2017.1396583

Cheever, N. A., Rosen, L. D., Carrier, L. M., \& Chavez, A. (20I4). Out of sight is not out of mind: The impact of restricting wireless mobile device use on anxiety levels among low, moderate and high users. Computers in Human Behavior, 37, 290-297. https://doi.org/10.1016/j.chb.2014.05.002 
Clayton, R. B., Leshner, G., \& Almond, A. (20I5). The extended iSelf: The impact of iPhone separation on cognition, emotion, and physiology. Journal of Computer-Mediated Communication, 20(2), II9-I35. https://doi.org/I0.1 I I I/jcc4.12109

Cooley, C. H. (1902). Human nature and the social order. Scribner's Sons.

Cumiskey, K. M., \& Ling, R. (20I5). The social psychology of mobile communication. In S. S. Sundar (Ed.), The handbook of the psychology of communication technology (pp. 228-246). John Wiley \& Sons. https://doi.org/10.1002/978I I I8426456.ch I0

Cushing, A. L. (20I I). Self extension and the desire to preserve digital possessions. Proceedings of the American Society for Information Science and Technology, 48, I-3. https://doi.org/I0.1002/meet.201 I.1450480I 304

Davidson, B. I., Shaw, H., \& Ellis, D. A. (2020). Fuzzy constructs in assessment: The overlap between mental health and technology "use." Psyarxiv. 10.31234/osf.io/6durk

Elhai, J. D., Dvorak, R. D., Levine, J. C., \& Hall, B. J. (2017). Problematic smartphone use: A conceptual overview and systematic review of relations with anxiety and depression psychopathology. Journal of Affective Disorders, 207, 25I-259. https://doi.org/I0.1016/j.jad.2016.08.030

Ellis, D. A., Davidson, B. I., Shaw, H., \& Geyer, K. (2019). Do smartphone usage scales predict behavior? International Journal of Human Computer Studies, 130, 86-92. https://doi.org/10.1016/j.ijhcs.2019.05.004

Freytag, A., Knop-Huelss, K., Meier, A., Reinecke, L., Hefner, D., Klimmt, C., \& Vorderer, P. (2020). Permanently online-always stressed out? The effects of permanent connectedness on stress experiences. Human Communication Research. Advance online publication. https://doi.org/I0.1093/hcr/hqaa0I4

Frith, J. (2019). A billion little pieces: RFID and infrastructures of identification. MIT Press.

Han, S., Kim, K. J., \& Kim, J. H. (20I7). Understanding nomophobia: Structural equation modeling and semantic network analysis of smartphone separation anxiety. Cyberpsychology, Behavior, and Social Networking, 20(7), 419-427. https://doi.org/10.1089/cyber.2017.0113

Hu, L. T., \& Bentler, P. M. (1999). Cutoff criteria for fit indexes in covariance structure analysis: Conventional criteria versus new alternatives. Structural Equation Modeling: A Multidisciplinary Journal, 6(I), I-55. https://doi.org/I0.1080/I07055 I 9909540 I I8

Hulme, M., \& Peters, S. (200I). Me, my phone and I: The role of the mobile phone. CHI 200 I Workshop: Mobile Communications: Understanding Users, Adoption, and Design (Pp. I-2). ACM.

Humphreys, L. (20I8). The qualified self: Social media and the accounting of everyday life. MIT Press.

Hunter, J. F., Hooker, E. D., Rohleder, N., \& Pressman, S. D. (20I8). The use of smartphones as a digital security blanket: The influence of phone use and availability on psychological and physiological responses to social exclusion. Psychosomatic Medicine, 80(4), 345-352. https://doi.org/I 0.1097/PSY.0000000000000568

James, W. (1890). Principles of psychology. Holt.

Johannes, N., Veling, H., Verwijmeren, T., \& Buijzen, M. (2019). Hard to resist?: The effect of smartphone visibility and notifications on response inhibition. Journal of Media Psychology, 3 I (4), 214-225. https://doi.org//0.1027//864-I 105/a000248

Kanthawala, S., Joo, E., Kononova, A., Peng, W., \& Cotten, S. (2019). Folk theorizing the quality and credibility of health apps. Mobile Media and Communication, 7(2), 175-194. https://doi.org//0.II77/20501579/8796859

Katz, J. E. (Ed.). (2003). Machines that become us: The social context of personal communication technology. Routledge. https://doi.org/I0.4324/9780203786826

Kuss, D. J., Kanjo, E., Crook-Rumsey, M., Kibowski, F., Wang, G. Y., \& Sumich, A. (2018). Problematic mobile phone use and addiction across generations: The roles of psychopathological symptoms and 
smartphone use. Journal of Technology in Behavioral Science, 3, I4I-I49. https://doi.org//0.1007/s4 I347-017-004I-3

Kwon, M., Kim, D. J., Cho, H., \& Yang, S. (20I3). The smartphone addiction scale: Development and validation of a short version for adolescents. PLOS ONE, 8(I2), e83558. https://doi.org/10.137I/journal.pone.0083558

Lanette, S., Chua, P. K., Hayes, G., \& Mazmanian, M. (2018). How much is “too much"?: The role of a smartphone addiction narrative in individuals' experience of use. Proceedings of the ACM on HumanComputer Interaction, 2(CSCW). https://doi.org/ I 0.I I45/3274370

LaRose, R. (2010). The problem of media habits. Communication Theory, 20(2), 194-222. https://doi.org/I0.IIII/j. I468-2885.20I0.01360.x

Lee, S., \& Sundar, S. S. (20I5). Cosmetic customization of mobile phones: Cultural antecedents, psychological correlates. Media Psychology, I8(I), I-23. https://doi.org//0.1080/15213269.2013.853618

Lepp, A., Barkley, J. E., \& Karpinski, A. C. (2014). The relationship between cell phone use, academic performance, anxiety, and satisfaction with life in college students. Computers in Human Behavior, 3I(I), 343-350. https://doi.org/I0.1016/j.chb.2013.10.049

McLuhan, M. (1962). The Gutenberg galaxy: The making of typographic man. University of Toronto Press.

Melumad, S., \& Pham, M. T. (2020). The smartphone as a pacifying technology. Journal of Consumer Research, 47(2), 237-255. https://doi.org// 0.1093/jcr/ucaa005

Morin, A. (2017). Toward a glossary of self-related terms. Frontiers in Psychology, 8(280). https://doi.org//0.3389/fpsyg.2017.00280

Mutchler, L. A., Shim, J. P., \& Ormond, D. (20II). Exploratory study on users' behavior: Smartphone usage. AMCIS 201 I Proceedings - All Submissions, 418. http://aisel.aisnet.org/amcis20I I_submissions/4I8

Nass, C., \& Moon, Y. (2000). Machines and mindlessness: Social responses to computers. Journal of Social Issues, 56(I), 8I-103. https://doi.org/I0.IIIII/0022-4537.00I53

Oksman, V., \& Rautiainen, P. (2003). "Perhaps it is a body part": How the mobile phone became an organic part of the everyday lives of Finnish children and teenagers. In J. E. Katz (Ed.), Machines that become us: The social context of personal communication technology (Pp. 293-308). Transaction Publishers.

Oulasvirta, A., \& Blom, J. (2008). Motivations in personalisation behaviour. Interacting with Computers, 20(I), I-16. https://doi.org/I0.1016/j.intcom.2007.06.002

Oyserman, D., Lewis, N. A., Yan, V. X., Fisher, O., O’Donnell, S. C., \& Horowitz, E. (2017). An identitybased motivation framework for self-regulation. Psychological Inquiry, 28(2-3), I39-147. https://doi.org//0.1080/1047840X.2017.1337406

Park, C. S., \& Kaye, B. K. (2019). Smartphone and self-extension: Functionally, anthropomorphically, and ontologically extending self via the smartphone. Mobile Media and Communication, 7(2), 2I5-23I. https://doi.org/I0.II77/2050I579/8808327

Pivetta, E., Harkin, L., Billieux, J., Kanjo, E., \& Kuss, D. J. (2019). Problematic smartphone use: An empirically validated model. Computers in Human Behavior, 100, 105-1 17. https://doi.org/I0.1016/j.chb.2019.06.013

Reinecke, L., Klimmt, C., Meier, A., Reich, S., Hefner, D., Knop-Huelss, K., Rieger, D., \& Vorderer, P. (2018). Permanently online and permanently connected: Development and validation of the Online Vigilance Scale. PLoS ONE, 13(I0), e0205384. https://doi.org/ I 0.137I/journal.pone.0205384

Revelle, W. (2019). psych: Procedures for personality and psychological research. Northwestern University. https://cran.r-project.org/package=psychVersion=I.9.12

Schnauber-Stockmann, A., \& Karnowski, V. (2020). Mobile devices as tools for media and communication research: A scoping review on collecting self-report data in repeated measurement 
designs. Communication Methods and Measures, I4(3), I45-164.

https://doi.org/I0.1080/I93/2458.2020.1784402

Schweitzer, F., Belk, R., Jordan, W., \& Ortner, M. (2019). Servant, friend or master? The relationships users build with voice-controlled smart devices. Journal of Marketing Management, 35(7-8), 6937I5. https://doi.org/10.1080/0267257X.2019.1596970

Seo, M., Kim, J. H., \& David, P. (2015). Always connected or always distracted? ADHD symptoms and social assurance explain problematic use of mobile phone and multicommunicating. Journal of Computer-Mediated Communication, 20(6), 667-68I. https://doi.org/I0. I I I I/jcc4. I 140

Sheth, J. N., \& Solomon, M. R. (20I4). Extending the extended self in a digital world. Journal of Marketing Theory and Practice, 22(2), I 23-I32. https://doi.org/I0.2753/MTPI069-667922020 I

Slater, M. D., Johnson, B. K., Cohen, J., Comello, M. L. G., \& Ewoldsen, D. R. (20I4). Temporarily expanding the boundaries of the self: Motivations for entering the story world and implications for narrative effects. Journal of Communication, 64(3), 439-455. https://doi.org/I 0.1 I I I/jcom. 12100

Swisher, K. (2020, November 27). Amazon wants to get even closer. Skintight. The New York Times. https://www.nytimes.com/2020/I I/27/opinion/amazon-halo-surveillance.html

Turkle, S. (2008). Always-on/always-on-you: The tethered self. In J. E. Katz (Ed.), Handbook of mobile communications and social change (PP. I2I-138). MIT Press.

Vanden Abeele, M. M. P. (2020). Digital wellbeing as a dynamic construct. Communication Theory. Advance online publication. https://doi.org/I0.1093/ct/qtaa024

Vanden Abeele, M. M. P., de Wolf, R., \& Ling, R. (2018). Mobile media and social space: How anytime, anyplace connectivity structures everyday life. Media and Communication, 6(2), 5-I4. https://doi.org/l 0.17645/mac.v6i2.1399

Venables, W. N., \& Ripley, B. D. (2002). Modern applied statistics with S. Springer. http://www.stats.ox.ac.uk/pub/MASS4

Verplanken, B. (2006). Beyond frequency: Habit as mental construct. British Journal of Social Psychology, 45(3), 639-656. https://doi.org/10.1348/014466605X49/22

Verplanken, B., \& Orbell, S. (2003). Reflections on past behavior: A self-report index of habit strength. Journal of Applied Social Psychology, 33(6), I3 I3-1330. https://doi.org/I0.I I I I/j. I559I816.2003.tb0195I.x

Verplanken, B., \& Sui, J. (2019). Habit and identity: Behavioral, cognitive, affective, and motivational facets of an integrated self. Frontiers in Psychology, 10, I 504. https://doi.org/I 0.3389/fpsyg.2019.01504

Vincent, J. (2006). Emotional attachment and mobile phones. Knowledge, Technology, and Policy, 19(I), 39_ 44. https://doi.org/I0.1007/s I2130-006-1013-7

Vishwanath, A., \& Chen, H. (2008). Personal communication technologies as an extension of the self: $A$ cross-cultural comparison of people's associations with technology and their symbolic proximity with others. Journal of the American Society for Information Science and Technology, 59(I I), I76I-I775. https://doi.org/I0.1002/asi.20892

Walsh, S. P., \& White, K. M. (2007). Me, my mobile, and I: The role of self- and prototypical identity influences in the prediction of mobile phone behavior. Journal of Applied Social Psychology, 37(I0), 2405-2434. https://doi.org/I0.I I I I/j.I559-1816.2007.00264.x

Walsh, S. P., White, K. M., \& Young, R. M. (2010). Needing to connect: The effect of self and others on young people's involvement with their mobile phones. Australian Journal of Psychology, 62(4), 194203. https://doi.org/10.1080/00049530903567229

Wang, W. (2017). Smartphones as social actors? Social dispositional factors in assessing anthropomorphism. Computers in Human Behavior, 68, 334-344. https://doi.org/I0.1016/j.chb.2016.1 I.022 
Waytz, A., Cacioppo, J., \& Epley, N. (2010). Who sees human? The stability and importance of individual differences in anthropomorphism. Perspectives on Psychological Science, 5(3), 219-232. https://doi.org/I0.1 I77//745691610369336

Wolniewicz, C. A., Tiamiyu, M. F., Weeks, J. W., \& Elhai, J. D. (2018). Problematic smartphone use and relations with negative affect, fear of missing out, and fear of negative and positive evaluation. Psychiatry Research, 262, 618-623. https://doi.org/10.1016/j.psychres.2017.09.058

Wood, W., Quinn, J. M., \& Kashy, D. A. (2002). Habits in everyday life: Thought, emotion, and action. Journal of Personality and Social Psychology, 83(6), I28I-1297. https://doi.org// 0.1037/002235I4.83.6.| $|28|$

Yildirim, C., \& Correia, A. P. (20I5). Exploring the dimensions of nomophobia: Development and validation of a self-reported questionnaire. Computers in Human Behavior, 49, I30-137. https://doi.org/10.1016/j.chb.2015.02.059

Yildirim, C., Sumuer, E., Adnan, M., \& Yildirim, S. (2016). A growing fear: Prevalence of nomophobia among Turkish college students. Information Development, 32(5), I322-I33I. https://doi.org/I0.I I77/02666669/5599025

\section{Author biographies}

Morgan Quinn Ross is a PhD student in the School of Communication at The Ohio State University. His research interests lie at the center of mobility, identity, and mobile communication.

Joseph B. Bayer is an assistant professor in the School of Communication and Translational Data Analytics Institute at The Ohio State University. He studies how social cognition is changing in conjunction with mobile technologies, social media, and social networks. 